\title{
Tax evasion and inequality: some theoretical and empirical insights
}

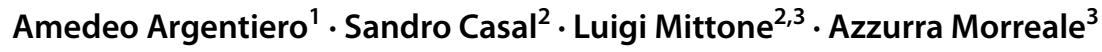 \\ Received: 6 August 2021 / Accepted: 6 August 2021 / Published online: 8 September 2021 \\ (๑) The Author(s), under exclusive licence to Springer-Verlag GmbH Germany, part of Springer Nature 2021
}

Keywords Tax evasion · Income inequality $\cdot$ Social capital $\cdot$ Institutional quality index $\cdot$ Tax compliance $\cdot$ Propensity forevasion

\section{Introduction}

Most taxation systems imply a redistribution of resources aimed at reducing economic inequality in society. Tax evasion represents a major source of inequality irrespective of the redistribution goal in a country. This Special Issue of Economics of Governance seeks to investigate the impact that some new challenges, strictly related to taxpayers' behaviour, may have on social equity and perceived fairness. Emphasis is placed on the behavioural determinants of tax compliance and the role of institutions and norms.

In particular, this Special Issue comprises three papers selected from among those presented during the 6th edition of the Shadow Economy Conference, which was named 'Tax Evasion and Economic Inequality' and took place in July 2019 in Trento, Italy.

The large variety of methods applied in the barely 50 papers accepted for presentations documented how research in tax evasion requires a wide perspective and a mix of techniques. Moreover, among the conference participants, there were not only economists (both empirical and behavioural) but also scholars from other disciplines (such as psychology, sociology and law) and some professionals and experts in the field (coming from the Italian Ministry of Economy and Finance and the Italian Revenue Agency). Indeed, as emphasised in the next sections, the conference theme on tax evasion and economic inequality may be read from different

\footnotetext{
The order of the authors is alphabetical.

Luigi Mittone

luigi.mittone@gmail.com

1 Faculty of Economics and Law, Kore University of Enna, Enna, Italy

2 Department of Economics and Management, University of Trento, Trento, Italy

3 School of Business and Management, LUT University, Lappeenranta, Finland
} 
perspectives, which, although apparently unrelated, may contribute to understanding how people pay taxes.

We hope this Special Issue will also stimulate scholars to pursue promising directions, building on the hints and inspirations that this editorial and each article provide. Hence, this editorial unfolds as follows: after introducing the concepts of economic inequality and tax evasion (Sect. 2) using data from Italy, we provide an empirical picture of the relationship between income inequalities and tax evasion (Sect. 3). Finally, we conclude with a brief commentary on each of the articles introduced in this Special Issue and call for further articles investigating the crucial relationship between inequality and tax evasion (Sect. 4).

\section{Tax evasion and inequality: an analysis through the behavioural economics lens}

In the last 50 years, the model proposed by Allingham and Sandmo (1972) has been considered the benchmark economic model representing tax behaviour (Luttmer and Singhal 2014). As usual in the neoclassical approach, the individual is represented as a self-interested agent who chooses the amount of income to report to the tax authority by trading off the expected utility of tax evasion against the certain utility of tax conformity. In this model, the parameters considered are the probability of detection, tax rate and sanction executed conditionally on the detection (Luttmer and Singhal 2014).

The representative taxpayer in this model is exclusively affected by economic reasons: when the penalties and the detection probability are low, the taxpayer has an economic incentive to evade. Therefore, according to such a classical approach, reducing economic incentives by increasing the probability of detection and/or the penalties effectively increases tax compliance (Bott et al. 2020).

Nevertheless, both policymakers and academics acknowledge the presence of non-monetary motivations that are also likely to affect tax compliance. The scientific contributions to analysing these factors that influence tax compliance have given rise to the stream of literature on 'tax morale' (Luttmer and Singhal 2014). Trying to make an extreme synthesis, it is possible to build two main groups of non-pecuniary factors that influence tax compliance from the perspective of the tax morale literature: the factors related to the social context and the factors that depend on the relationship between taxpayers and the Tax Authority.

The first group includes those situations where the taxpayers are induced to comply because of direct interaction with other taxpayers for different reasons, such as shame aversion (Casal and Mittone 2016) or imitative behaviours (Myles and Naylor 1996; Mittone and Patelli 2000) and those situations where intrinsic costs (Dwenger et al. 2016) or related feelings, such as moral and duty (Engel et al. 2020), may play a role.

The second group of non-pecuniary features that can influence tax compliance includes those factors related to the interaction between the taxpayers and the autority (Kirchler et al. 2008). All these factors can broadly be condensed into a unique category: the perceived fairness of the State. More precisely, all the different 
psychological dimensions of the relationship between the taxpayers and the State, which have been investigated by the literature on tax morale, can in some way be grouped under the common umbrella of the feeling to be treated more or less fairly by the State. In fact, the two main drivers of tax compliance due to an interaction between the taxpayers and the State highlighted by the tax morale literature (i.e. the good use done by the State of the tax yield collected and the maintaining of parity among taxpayers) are strictly linked to the same mechanism, that is, the maintenance of a positive reputation of the State among the citizens.

From these considerations, it appears clear that empowering the psychological triggers of tax compliance (i.e. the triggers falling under the afore-mentioned tax morale) is a very effective tool for the State to reduce tax evasion. In fact, many researchers (see, for instance, Alm et al. 1992; Andreoni et al. 1998; Bott et al. 2020) concur that tax morale can explain why the level of tax compliance is often higher than the expected value computed, applying the standard expected utility maximisation approach (i.e. assuming that people are only motivated by the fear of being detected and punished).

Nevertheless, for policymakers, exploiting the advantages of tax morale may be challenging. In particular, one of the main sources of taxpayer dissatisfaction is perceived inequality (Bloomquist 2003). Specifically, taxpayer dissatisfaction may arise from different sources of perceived inequality, namely, 'exchange inequality, vertical inequality and horizontal inequality’ (e.g. Kinsey and Grasmick 1991).

First, people may perceive that the level of tax paid is more than the benefits (regarding public goods and services) received (exchange inequality) (Bloomquist 2003; Wenzel 2003). The perception of such a type of inequality may increase tax evasion. Indeed, several researchers have reported the existence of an opposite relationship between perceived exchange inequality and tax compliance (e.g. Alm et al. 1990; Scholz and Lubell 1998). Using survey data, Lewis (1979) reported that healthier people show a strong disaffection towards the tax system and more in general towards taxes. This finding suggests that taxpayer dissatisfaction grows as the gap between the amount of taxes paid and the number (and value) of public services received increases (Bloomquist 2003).

Second, the perception of an unfair tax system may arise when 'equal treatment of equals' (Kaplanoglou and Newbery 2008, p. 2) is not guaranteed (horizontal inequality or inequality among groups). Horizontal inequality is related to fiscal pressure 'for members relative to others within a given social stratum' (Wenzel 2003, p. 44). That is, taxpayer dissatisfaction may arise regarding taxation where individuals who are likely to have equal economic conditions perceive different fiscal pressures.

Finally, another kind of perceived inequality that can, in turn, reduce tax compliance is vertical inequality (i.e. inequality among individuals). Vertical inequality is related to fiscal pressure 'for certain social strata relative to other strata' (Wenzel 2003 , p. 44). Here, such a source of inequality can be induced by the heterogeneity of the income levels of the citizens. Indeed, since populations have heterogeneous incomes, some part of the population can be privileged by a specific tax regime. Simultaneously, another part of the population can perceive the same tax regime as unfair (Engel et al. 2020). In the words of Engel et al. (2020, p. 81), 'Worse even: 
those privileged by the tax regime might anticipate that those disadvantaged will evade taxes and might themselves evade taxes in response'.

In summary, what emerges from this discussion is that inequality (regardless of its specific nature) plays a central role in supporting or depressing tax compliance. Indeed, the behavioural and economic literature on tax compliance concurs with viewing inequality as 'an evasion determinant' (Bloomquist 2003, p. 4). On the one hand, as the perception of individuals of inequality increases, taxpayers start to evade or evade more. On the other hand, more evasion is positively correlated with more inequality (Bloomquist 2003).

Moreover, the picture is even more complicated when at least two sources of inequality interact with each other (e.g. exchange inequality interacts with horizontal or vertical inequality). For instance, in a laboratory experiment, Moser et al. (1995) found that horizontal inequality interacted with exchange inequality and affected the correct declared income such that participants declared less income as tax rates increased, but only when they were treated inequitably compared to the others (i.e. when others' tax rate was lower than their tax rate).

\section{Tax evasion and inequality: an analysis through empirical data}

To directly picture the relationship between inequality and tax evasion, we analysed some stylised facts related to Italy. This country is particularly representative of both tax evasion and income inequality, given that tax evasion amounted to almost 90 billion euros per year from 2010 to 2014, and in 2014, the share of taxpayers declaring an income above 200,000 euros was only $0.25 \%$ of the total (source: Italian Ministry of Economy). For what it regards the degree of income inequality in 2019 , Italy ranked ${ }^{1} 26$ th in a group made of 34 European countries. In 2019, only Albania, Lithuania, Serbia, Latvia, Montenegro, Romania, Bulgaria and Turkey had a less equitable income distribution than Italy. More precisely, in Italy, $20 \%$ of the richest population received on average about six times as much as the income of the poorest $20 \%$ of the population, while there are quite many European countries with a per-capita GDP not too far from the Italian one (e.g. Finland, which in 2019 had a per capita GDP $14 \%$ higher than the Italian one ${ }^{2}$ ) where this ratio is halved. In Fig. 1, we report a graph showing the different levels of income distribution among EU nations.

To make the Italian situation even more peculiar regarding income distribution, it is important to underline that while in many European countries, the inter-regional

\footnotetext{
1 The ranking is based on data from Eurostat and are referred to the "ratio of total income received by the $20 \%$ of the population with the highest income (top quintile) to that received by the $20 \%$ of the population with the lowest income (lowest quintile). Income must be understood as equivalized disposable income." (Source Eurostat: https://ec.europa.eu/eurostat/web/products-datasets/-/tespm151 accessed July 19, 2021).

2 More precisely in Italy in 2019 the per-capita GDP was \$ 42,663 (PPP) while in the same year in Finland was \$ 48,689 (PPP) (Source World Bank: https://data.worldbank.org/indicator/NY.GDP.PCAP.PP. CD?locations $=$ EU accessed July 19, 2021).
} 
EU Income quintile share ratio 2019

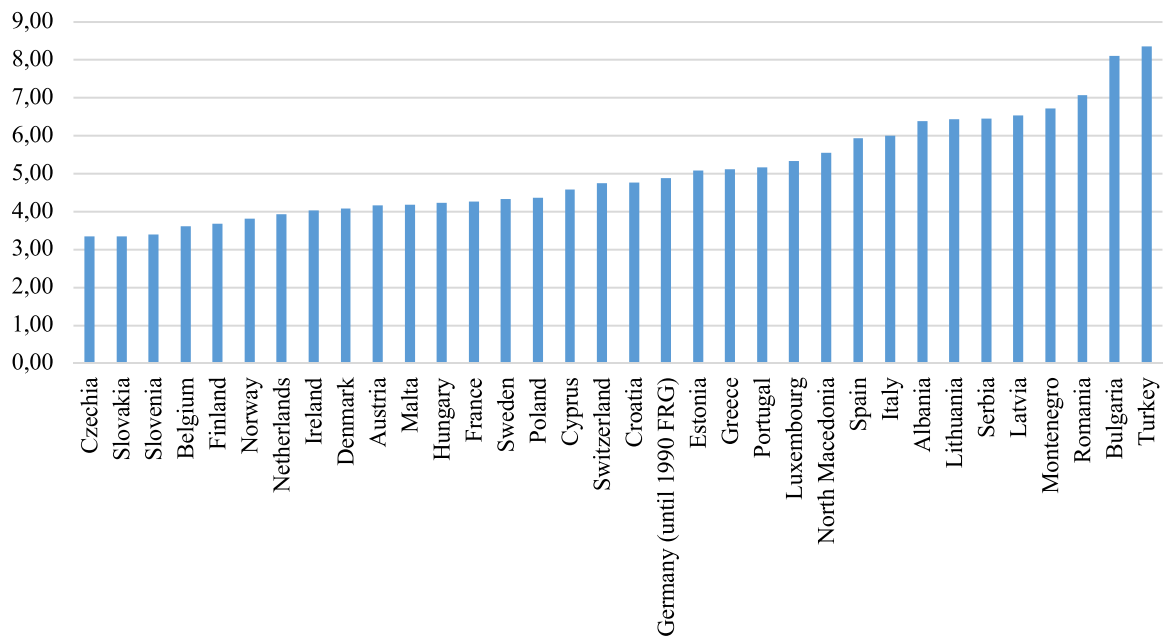

Fig. 1 Income distribution European nations (2019)

distribution of income is relatively homogenous, there are big differences across regions in Italy. In fact, it is well known that the northern Italian regions are much richer than the Southern regions. There is a concentration of GDP in a few Northern regions: for instance, in Lombardy, which is the richest among the large Italian regions (i.e. not considering the Valle d'Aosta and the Province of Bolzano), the GDP per capita in 2018 was 38,500 euros, while in Calabria, which, in the same year, was the poorest Italian region, the GDP per was equal to 17,000 euros. ${ }^{3}$ Moreover, we will see later that the Southern Italian regions are characterised not only as being poorer than the Northern regions but also as being the regions where there are the highest internal inequalities in income distribution.

Given these premises, Italy offers an interesting laboratory to empirically investigate the relationship between poverty, inequality and tax evasion. More precisely, it is interesting to check whether our fundamental hypothesis, anticipated in the previous section, regarding the correlation between inequality and tax evasion is confirmed by empirical data. ${ }^{4}$ It is worth underlining that the main weakness of the correlative nature of our empirical exercise is related to the fact that we cannot disentangle the direction of the causal relationship between inequality and tax evasion. Alternatively, we cannot demonstrate whether tax evasion is a consequence of income inequalities or vice versa. In fact, when tax evasion is largely widespread, it can deeply damage the correct functioning of the economic system mainly because

\footnotetext{
${ }^{3}$ Source Eurostat: https://ec.europa.eu/eurostat/documents/2995521/10474907/1-05032020-AP-EN.pdf/ 81807e19-e4c8-2e53-c98a-933f5bf30f58 (accessed July 19, 2021).

${ }^{4}$ We will check this hypothesis only from a correlation perspective, nevertheless we believe that such empirical evidence are surely informative about this phenomenon.
} 


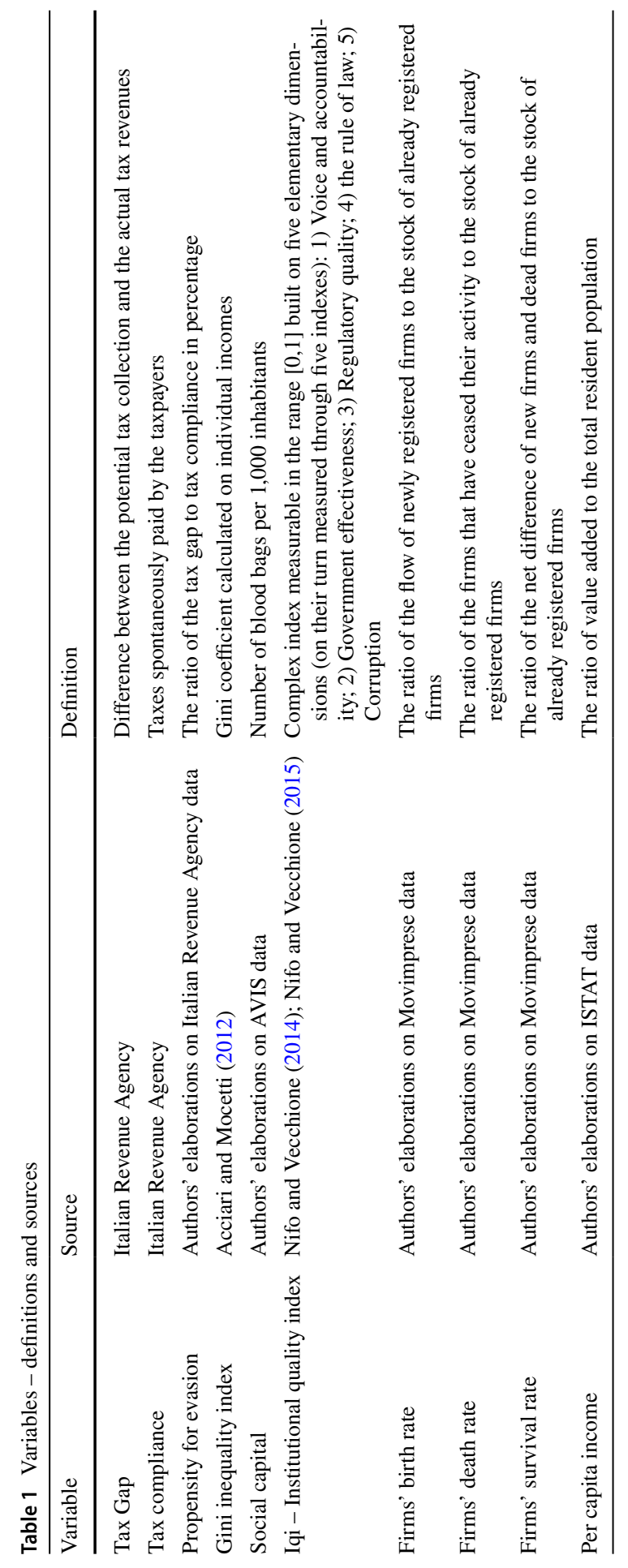




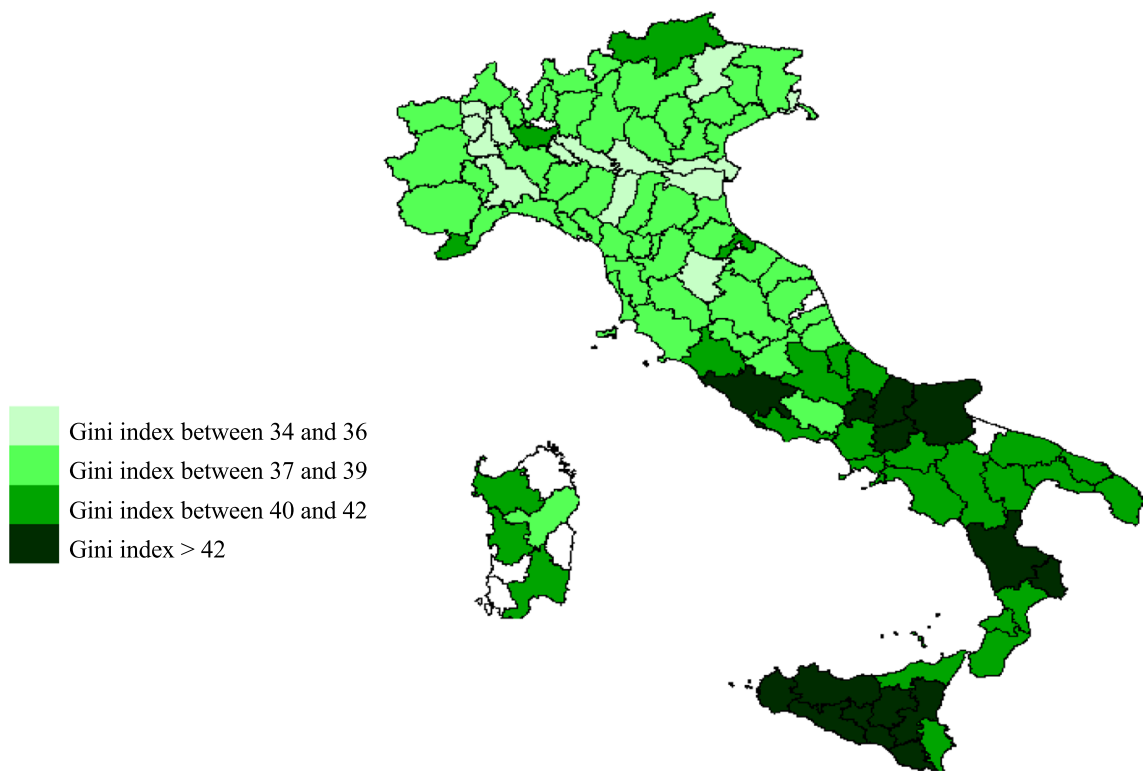

Fig. 2 Average provincial income inequality in Italy (2005-2011)

it interferes with the market mechanisms that sustain competition, thereby generating a large array of negative economic consequences (Slemrod 2007; Alm 2014).

Our empirical analysis is based on a panel data set containing annual observations from 103 Italian provinces (NUTS-3 level) over the 2005-2011 period. The definitions and sources of the variables used in our study are described in detail in Table 1.

Following Argentiero et al. (2020), we measure tax evasion through propensity for evasion, which is given by the ratio between the tax gap and tax compliance (i.e. the spontaneous tax revenues), whereas income inequality data have been taken by Acciari and Mocetti (2012), who have calculated the Gini coefficient index on total gross incomes composed of employment, self-employment, business incomes, incomes from participation in the firms, pension incomes and incomes from land and buildings. ${ }^{5}$ In Fig. 2, we report a map of the Italian provinces with the corresponding average Gini index scores (Acciari and Mocetti 2012). ${ }^{6}$

Table 2 shows some descriptive statistics relating to the variables from 2005 to 2011 in Italy. The propensity for evasion is on average more than $40 \%$, but there is

\footnotetext{
5 Incomes subject to substitute taxation, incomes of those with only exempt incomes, incomes of those that own only the main residence and the incomes of the owners of land and buildings with an income of less than 500 euros per year are not included.

6 The data are referred to the period 2005-2011 but in the last 10 years there are no reasons to think that any relevant change should have occurred for what it regards the income distribution. Moreover, our aim is not to describe the Italian situation today but to use the Italian case as an example for a better understanding of the relationship between income inequalities and tax evasion.
} 
Table 2 Some descriptive statistics

\begin{tabular}{llrrrrr}
\hline Variable & Observations & Mean & Median & Min & Max & $\begin{array}{c}\text { Coefficient } \\
\text { of variation }\end{array}$ \\
\hline Propensity for evasion & 721 & & & & & \\
Gini inequality index & 721 & 39.62 & 39.70 & 10.01 & 71.17 & 0.30 \\
Social capital & 721 & 38.52 & 35.05 & 0.30 & 120.29 & 0.65 \\
Iqi - Institutional quality & 700 & 0.59 & 0.66 & 0 & 1 & 0.37 \\
$\quad$ index & 721 & & & & & \\
Firms' birth rate & 721 & 7.60 & 7.49 & 5.09 & 13.61 & 0.15 \\
Firms' death rate & 721 & 0.06 & 0.18 & -9.36 & 4.60 & 24.60 \\
Firms' survival rate & 721 & $22,506.49$ & $22,671.75$ & $12,527.42$ & $46,850.34$ & 0.25 \\
Per capita income & & & & & & \\
\hline
\end{tabular}

huge variability among the provinces over the time span considered, ranging from 10 to $71 \%$, with a higher concentration of the phenomenon in the Islands (Sicily and Sardinia). In the Southern part of the country, the mean value is around 50\%, whereas propensity for evasion amounts, on average, to $30 \%$ in the North-East Regions, 35\% in the North-West Regions and $40 \%$ in the Central Regions. This evidence is furtherly shown in the cartogram reported in Fig. 3, where the different colours identify the distribution of tax evasion over the Italian regions (NUTS-2 level).

Also, income inequality, which figures on average at $39 \%$, is mainly concentrated in the Islands and the southern part of the country, although with lesser variability

Tax evasion $>33 \%$

Tax evasion between $33 \%$ and $47 \%$

Tax evasion $>47 \%$

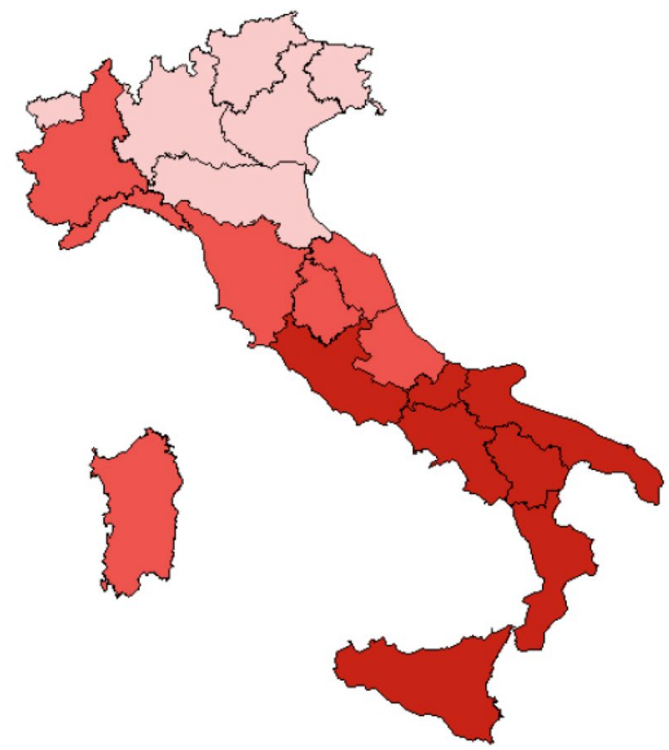

Authors' elaboration on Italian Revenue Agency data

Fig. 3 Average propensity for evasion in Italy (2005-2011) 


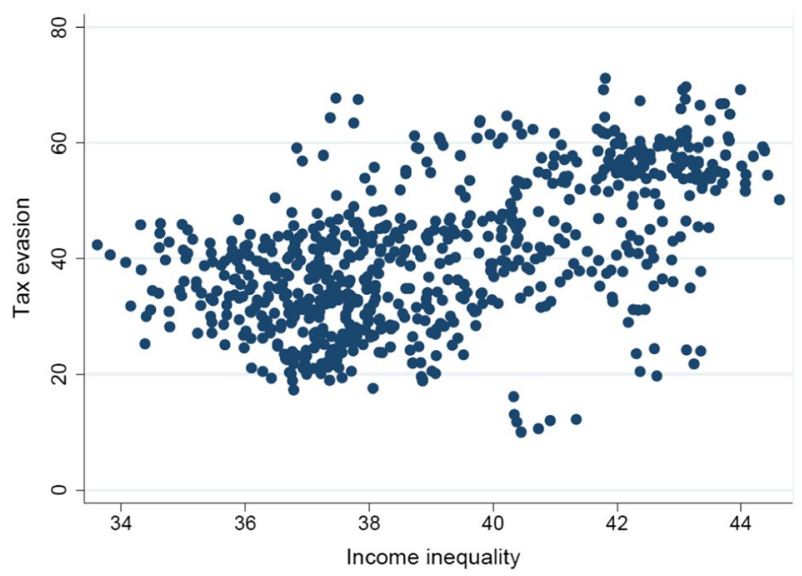

Fig. 4 Correlation between income inequality and tax evasion

than tax evasion, with an average value of Gini coefficient around $41 \%$, whereas in the other areas of the country the inequality measures on average $37 \%$.

Figure 4 shows a scatter plot between the propensity for evasion and the Gini coefficient in the time span considered for the Italian provinces.

Apart from a few outliers, a positive correlation between income inequality and tax evasion in Italy is worth noting. We tested the statistical significance of this pairwise correlation, and we found a value of the Pearson coefficient of 0.55 at $1 \%$ significance.

Given the geographical heterogeneity found in the descriptive statistics, we disaggregate the above pairwise Pearson correlation between tax evasion and income inequality at a macro-area level. The results are summarised in Table 3.

This picture clearly shows that the positive correlation between tax evasion and income inequality is driven by the Southern provinces and Islands. These areas, which exhibit higher tax evasion and income inequality than the other parts, also have a smaller share of income held by the low tail of the distribution (Acciari and Mocetti 2012), a lower per capita income (16,622.21 in the South, 16,354.37 in the Islands compared to 23,548.01 in the Centre, 27,381.2 in the North-East and 26,098.2 in the North-West), a smaller social capital level (22.31 in the South,

Table 3 Pairwise pearson correlations - tax evasion and income inequality for italian macro-areas

\begin{tabular}{ll}
\hline MACRO-AREA & $\begin{array}{l}\text { PAIRWISE PEAR- } \\
\text { SON CORRELA- } \\
\text { TIONS }\end{array}$ \\
\hline North-east & -0.02 \\
North-west & -0.12 \\
Centre & 0.03 \\
South & $0.48^{* * *}$ \\
Islands & $0.55^{* * *}$
\end{tabular}

$* * *, * *$ and $*$ indicate that the index is significant at the $1 \%, 5 \%$ and $10 \%$ levels of significance, respectively 
24.78 in the Islands, compared to 37.08 in the Centre, 49.33 in the North-East and 52.85 in North-West) and a lower institutional quality index ( 0.48 in the South, 0.32 in the Islands compared to 0.74 in the Centre, 0.63 in the North-East and 0.65 in the North-West).

The low level of social capital and the poor quality of the institutions weaken both the relationship among the taxpayers and the link between them and the Government; thus, affecting tax morale (see Alm and Gomez 2008; Bonatti and Lorenzetti 2018). All these features described so far make possible the role of tax evasion in determining income inequality since evading results in a transfer of income from fixed income earners to self-employees. Nevertheless, income inequality can also cause tax evasion. The presence of high inequalities in income distribution can make tax evasion a real possibility of economic survival. This aspect is also highlighted by the data reported in Table 2 on birth, mortality and business survival: the firms' birth and death rates are quite similar across the Macro-Areas, whereas the survival rate is even higher in the South (0.11) compared to the North-East $(-0.20)$, despite the differences in the per capita incomes. A possible explanation for this puzzling evidence is the presence of a hidden income, which is the basis of tax evasion.

\section{Brief commentary on the articles featured in the Special Issue and Concluding Remarks}

The first paper we present, written by James Alm, is a good primer on the current state of technology and tax evasion. The author highlights how tax evasion may change according to the development of new technology. In a recent paper, Alstadsæter et al. (2019) show how tax evasion is highly concentrated among the rich, and James Alm goes a step forward and argues that effective wealth inequality will likely increase since, due to access to new technology, the wealthy will have more opportunities to evade taxes.

The second paper, written by Janina Enachescu, Ziga Puklavec, Jerome Olsen and Erich Kirchler, enters into the psychological domain, and it studies the effect of (induced) incidental emotions on tax compliance decisions. Unlike integral emotions, incidental emotions are characterised by not having to be experienced in the decision context (i.e. tax behaviour in our context) but may still play a role in the final behaviour. So far, behavioural research has proved the role of integral emotions in tax compliance (particularly related to the abovementioned perceived inequality); this paper approach goes one step forward by analysing the role of the second type of emotions.

Finally, Emmanuelle Deglaire, Peter Daly and Le Lec Fabrice test the effect of being exposed to tax dilemmas on general attitudes towards taxation and tax compliance intentions, with a particular focus on how (tax) history and decision influences attitudes towards taxation, which focuses particular attention on 'fiscally unexperienced' taxpayers who may have a distorted perception of exchange inequality.

The papers in this Special Issue represent a step towards a better understanding of the role played by perceived inequalities as a bridge that reduces the gap between the two already mentioned streams of literature on tax morale: the one 
about the interaction between the taxpayers and the government and the one related to the interaction between taxpayers. In fact, at the roots of the psychological drivers, which sustain tax evasion due to some forms of perceived inequality, there is on one side the perceived role played by the tax system and on the other side a comparison between the conditions (and the fiscal treatments) of the individual taxpayers with their fellows. We encourage further research to continue in this regard.

\section{References}

Alstadsæter A, Johannesen N, Zucman G (2019) Tax evasion and inequality. Am Econ Rev 109(6):2073-2103

Acciari P, Mocetti S (2012) Una mappa della disuguaglianza del reddito in Italia. Politica Economica 28(3):307-343

Allingham MG, Sandmo A (1972) Income Tax Evasion: A Theoretical Analysis. J Public Econ $1(3-4): 323-338$

Alm J, Gomez JL (2008) Social capital and tax morale in Spain. Econ Anal Policy 38(1):73-87

Alm J, Bahl R, Murray MN (1990) Tax structure and tax compliance. Rev Econ Stat 72(4):603-613

Alm J, McClelland GH, Schulze WD (1992) Why do people pay taxes? J Public Econ 48(1):21-38

Alm, James, (2014), Tax evasion, labor market effects, and income distribution, IZA World of Labor, 91.

Andreoni J, Erard B, Feinstein J (1998) Tax compliance. J Econ Lit 36(2):818-860

Argentiero A, Chiarini B, Marzano E (2020) Does tax evasion affect economic crime? Fisc Stud 41(2):441-482

Bloomquist, K. M. (2003). Tax evasion, income inequality and opportunity costs of compliance. In Proceedings. Annual Conference on Taxation and Minutes of the Annual Meeting of the National Tax Association (Vol. 96, pp. 91-104). National Tax Association.

Bonatti L, Lorenzetti L (2018) The co-evolution of tax evasion, social capital and policy responses: a theoretical approach. Int Rev Econ 65(3):381-401

Bott KM, Cappelen AW, Sørensen EØ, Tungodden B (2020) You've got mail: a randomized field experiment on tax evasion. Manage Sci 66(7):2801-2819

Casal S, Mittone L (2016) Social esteem versus social stigma: The role of anonymity in an income reporting game. J Econ Behav Organ 124:55-66

Dwenger N, Kleven H, Rasul I, Rincke J (2016) Extrinsic and intrinsic motivations for tax compliance: Evidence from a field experiment in Germany. Am Econ J Econ Pol 8(3):203-232

Engel C, Mittone L, Morreale A (2020) Tax morale and fairness in conflict an experiment. J Econ Psychol 81:102314

Kaplanoglou G, Newbery DM (2008) Horizontal inequity and vertical redistribution with indirect taxes: The Greek case. Fisc Stud 29(2):257-284

Kirchler E, Hoelzl E, Wahl I (2008) Enforced versus voluntary tax compliance: The "slippery slope" framework. J Econ Psychol 29(2):210-225

Kinsey KA, Grasmick HG, Smith KW (1991) Framing Justice: Taxpayer Evaluations of Personal Tax Burdens. Law Soc Rev 25:845-873

Lewis A (1979) An empirical assessment of tax mentality. Public Finance = Finances Publiques 34(2):245-257

Luttmer EF, Singhal M (2014) Tax morale. J Econ Perspect 28(4):149-168

Mittone, L., \& Patelli, P. (2000). Imitative behaviour in tax evasion. In Economic simulations in swarm: Agent-based modelling and object oriented programming (pp. 133-158). Springer, Boston, MA.

Moser, D. V., Evans III, J. H., \& Kim, C. K. (1995). The effects of horizontal and exchange inequity on tax reporting decisions. Accounting Review, 619-634.

Myles GD, Naylor RA (1996) A model of tax evasion with group conformity and social customs. Eur J Polit Econ 12(1):49-66 
Nifo A, Vecchione G (2014) Do institutions play a role in skilled migration? The Case of Italy. Reg Stud 48(10):1628-1649

Nifo A, Vecchione G (2015) Measuring institutional quality in Italy. Rivista Economica Del Mezzogiorno 29(1-2):157-182

Scholz JT, Lubell M (1998) Adaptive political attitudes: Duty, trust, and fear as monitors of tax policy. Am J Political Sci 42(3):903-920

Slemrod J (2007) Cheating ourselves: the economics of tax evasion. J Econ Perspect 21(1):25-48

Wenzel M (2003) Tax compliance and the psychology of justice: Mapping the field. Ashgate Publishing, Farnham

Publisher's Note Springer Nature remains neutral with regard to jurisdictional claims in published maps and institutional affiliations. 